\title{
FRUTOLIGOSSACARÍDEOS: FIBRAS ALIMENTARES ATIVAS
}

ADERLEY SERENITA SARTORI DA SILVA*

PATRÍCIA HAAS*

NALDERI T. SARTORI**

ALEX A. ANTON***

ALÍCIA DE FRANCISCO****

\begin{abstract}
O objetivo desta revisão foi evidenciar a importância da utilização de frutoligossacarídeos (FOS) na alimentação humana e apresentar seus efeitos como ingredientes prebióticos. Foram abordados sua estrutura química, formas de obtenção industrial, propriedades químicas e físico-químicas dos FOS, efeitos na saúde humana, valor calórico e toxicidade. É inquestionável a comprovação das propriedades funcionais atribuída aos FOS, principalmente sua ação como fibra alimentar, diante dos resultados narrados pela literatura dos últimos 15 anos. Muitos estudos têm sido conduzidos para assegurar os efeitos dos FOS sobre a microbiota intestinal, sua atividade anticarcinogênica e sobre as taxas de colesterol e glicemia no sangue. Acredita-se que conforme os estudos se tornem cada vez mais conclusivos a indústria aumentará consideravelmente a oferta de alimentos enriquecidos com essa fibra alimentar nutricionalmente ativa.
\end{abstract}

PALAVRAS-CHAVE: FRUTOLIGOSSACARÍDEOS; INULINA; PRE-BIÓTICOS; FIBRAS ALIMENTARES.

* Doutoranda em Ciência dos Alimentos, Laboratório de Ciência e Tecnologia de Cereais (CERES), Departamento de Ciência e Tecnologia de Alimentos (CAL), Centro de Ciências Agrárias (CCA), Universidade Federal de Santa Catarina (UFSC), Florianópolis, SC (e-mail: aderley@hotmail.com; phaas@ig.com.br).

** Professora, Departamento de Farmácia, Universidade de Cuiabá (UNIC), Cuiabá, MT (e-mail: nalderi@hotmail.com).

*** Mestrando em Food Science, Faculty of Agricultural \& Food Sciences, University of Manitoba, Canada (e-mail: umanton@cc.umanitoba.ca).

**** Professora do Programa de Pós-Graduação em Ciência dos Alimentos, CERES/ CAL/CCA/UFSC, Florianópolis, SC (e-mail: aliciadf@gmail.com). 


\section{INTRODUÇÃO}

Os frutoligossacarídeos (FOS) são componentes de origem natural e sua biosíntese ocorre amplamente na natureza. Podem ser encontrados em quantidades expressivas em alimentos como, cebola, banana, alcachofra, alho, raízes de almeirão, beterraba (GIBSON e ROBERFROID, 1995; HATERMINK, VANLAERE e ROMBOUTS,1997) e na raiz da yacon (GOTO et. al., 1995).

O emprego e a utilização de FOS como ingredientes alimentares tem crescido consideravelmente devido suas características de fibra, além de não interferirem nas propriedades organolépticas dos produtos (NINESS, 1999). Muitas bebidas lácteas, doces, balas, sobremesas e geléias, principalmente as fabricadas no Japão, apresentam FOS em sua formulação (TANAKA e MATSUMOTO, 1998).

O notável interesse pelos FOS advém do fato desses compostos serem resistentes às enzimas digestivas e portanto não-digeridos pelo organismo humano (MOLIS, 1996). Conseqüentemente, chegam ao intestino grosso intactos e podem ser fermentados pelas bactérias anaeróbicas presentes no cólon (ROBERFROID, 1999). São chamados de "açúcares nãoconvencionais" e têm impacto na indústria de alimentos devido às suas excelentes características funcionais (SPIEGEL et. al., 1994).

A ingestão média diária per capita de FOS é de 2 a $4 \mathrm{~g}$ para norte americanos e 2 a $12 \mathrm{~g}$ para europeus (GIBSON, WILLIS e VAN LOO, 1994). No Brasil ainda não há dados relevantes com relação à quantidade ingerida ou recomendações dietéticas.

O objetivo desta revisão foi abordar a importância da utilização de FOS na alimentação humana e apresentar seus efeitos como ingrediente prebiótico.

\section{ESTRUTURA QUÍMICA DOS FRUTOLIGOSSACARÍDEOS}

Quimicamente os FOS são formados por oligômeros de frutose que são compostos de 1cestose, nistose e frutofuranonosil nistose em que as unidades de frutosil são ligadas na posição $\beta(2-1)$ da sacarose, o que os distingue de outros oligômeros (YUN, 1996). Esse tipo de ligação confere aos FOS a resistência à digestão ou hidrólise digestiva (FAGUNDES e COSTA, 2003).

A síntese dos frutoligossacarídeos nas plantas inicia-se a partir da transferência de uma unidade de frutose entre duas moléculas de sacarose, portanto alguns FOS apresentam uma molécula de glicose na extremidade da cadeia (GIBSON e ROBERFROID, 1995).

O grau de polimerização (GP), definido pelo número de unidades de monossacarídeos, é usado para definir e classificar as moléculas de FOS e inulina, sendo que os FOS apresentam GP $<10$ e a inulina GP de 2 a 60 (SPIEGEL, ROSE e KARABELL, 1994; YUN, 1996).

\section{OBTENÇÃO INDUSTRIAL DE FRUTOLIGOSSACARÍDEOS}

Sob o ponto de vista industrial, visando sua comercialização, os FOS podem ser obtidos a partir da inulina ou reação enzimática de transfrutosilação em resíduos de sacarose pela ação da enzima $\beta$-frutofuranosidase. No primeiro caso, efetua-se hidrólise enzimática controlada de moléculas de inulina com a enzima inulinase. Esse processo é utilizado para obtenção do produto chamado Raftilose $^{\circledast}$ (Orafti da Bélgica), ou Frutafit (produzido pela Imperial-Suikner Unie da Holanda). O GP desses produtos varia de 01 a 07 unidades de frutosil (BORGES, 2001). Os FOS formados pela ação da enzima $\beta$-frutofuranosidase contém GP entre 2 a 4 unidades de frutosil unidas por ligações ß 2-1 com resíduo de glicose terminal. Esse FOS, produzido no Japão, é comercializado como 
Neosugar, Meioligo e Nutraflora (Meiji Seika Co.) Na Europa é produzido e comercializado o Actilight pela Béghin Meiji Industries (HARTEMINK, VANLAERE e ROMBOUTS, 1998).

Segundo YUN (1996) as enzimas para a obtenção industrial de FOS são provenientes de plantas (aspargo, cebola, beterraba), ou de microrganismos (Aspergillus sp, Aureobalidium sp, Fusarium sp).

\section{PROPRIEDADES QUÍMICAS E FÍSICO-QUÍMICAS}

É importante distinguir inulina e FOS, pois suas propriedades físicas e aplicações em processos da indústria alimentícia são bastante diferentes. A inulina praticamente não tem sabor doce, sua consistência e baixa solubilidade em água a torna excelente substituto para gorduras principalmente em formulações de sorvete (ZULETA e ZAMBUCETI, 2006).

O tamanho das cadeias de inulina e de FOS também é responsável pelas diferentes propriedades desses compostos. A inulina é menos solúvel, apresenta cadeias longas (GP até 60) e capacidade para formar microcristais quando misturada com água e leite (GIBSON, WILLIS e VAN LOO, 1994). Esses microcristais formam mistura cremosa que dá a sensação de presença de gordura (NINESS, 1999). Os FOS, por sua vez, apresentam cadeias curtas (GP 2-9) e são altamente higroscópicos. Sua capacidade de retenção de água é superior à da sacarose e similar à do sorbitol. Tratando-se de carboidratos não-redutores não participam nas reações de Maillard (DREVON e BORNET, 1992). Essas fibras alimentares são altamente estáveis, suportam pH acima de $3 \mathrm{e}$ temperatura superior a $140^{\circ} \mathrm{C}$ (BORNET, 1994). Sua solubilidade em água atinge $80 \%$ a $25^{\circ} \mathrm{C}$. Também são solúveis em etanol a $80 \%, \mathrm{pH} 2$ e $0^{\circ} \mathrm{C}$, diferentemente de outros polissacarídeos (VAN LOO et al., 1998; QUINTEROS, 2000).

Os FOS são ingredientes alimentares ideais para a indústria de alimentos por permitirem aplicação em várias áreas. São indicados para formulações dietéticas (como sorvetes, cremes vegetais, patês e sobremesas) e adicionados em barras de cereais e biscoitos para elevar o conteúdo de fibras alimentares, além de bebidas lácteas e leites fermentados (BORNET, 1994). Também podem ser empregados em produtos alimentares para animais (STRICKLING et al., 2000).

A utilização de FOS com sucesso na indústria de alimentos se deve a inúmeras propriedades. Resistem a processos térmicos (pasteurização), são considerados isentos de calorias (1 a $1,5 \mathrm{Kcal} / \mathrm{g}$ ), não são cariogênicos, não cristalizam, não precipitam nem deixam sabor residual (MOLIS et al., 1996; YUN, 1996).

Como fibras alimentares podem ser adicionadas a qualquer tipo de alimento sem acrescentar sabores ou alterar a viscosidade do produto final. Resistem à digestão, mas são rapidamente fermentadas pelas bactérias presentes no cólon. Apresentam alta dispersibilidade em água, atuam aumentando o bolo fecal e reduzindo a incidência de constipação (PROSKY e HOEBREGS, 1999; SCHNEEMAN, 1999).

Estudos de HONDO, OKUMURA e YAMAKI (2000) indicam a possibilidade de produção de vinagre de yacon com FOS contidos no próprio yacon. Há também a possibilidade da suplementação de alimentos infantis com FOS de alto peso molecular com o intuito de facilitar o trânsito intestinal de recém nascidos (MORO et al., 2002).

\section{EFEITOS DOS FRUTOLIGOSSACARÍDEOS COMO PREBIÓTICOS E NA SAÚDE HUMANA}

A literatura tem comprovado propriedades funcionais dos FOS como, redução dos níveis de colesterol e do teor de glicose sanguíneas, redução da pressão sanguínea e melhor absorção do cálcio e magnésio (PEREIRA e GIBSON, 2002; COUNDRAY et. al., 2003). 
Os FOS não são digeridos pelo trato gastrintestinal humano e ao chegarem ao cólon estimulam beneficamente o crescimento e fortalecimento de bactérias específicas presentes no intestino (GIBSON e ROBERFROID, 1995). As bifidobactérias secretam a $\beta$-frutosidase, que seria a enzima responsável pela hidrólise dos FOS (ROBERFROID, 1993).

GIBSON e ROBERFROID (1995) constataram as características bifidogênicas dos FOS em humanos, usando dose de $15 \mathrm{~g}$ por dia como suplementação da dieta. As contagens médias de bifidobactérias aumentaram enquanto houve redução significativa de bacteróides, fusobactérias e Clostridium sp. Conforme os autores haveria maior aproveitamento desses compostos pelas bifidobactérias e, portanto, ocorreriam mudanças no ecossistema colônico desfavoráveis às bactérias nocivas.

O mecanismo pelo qual ocorre a inibição de microrganismos patogênicos (exógeno ou endógeno) pode ser explicada pela redução do $\mathrm{pH}$ no lúmen intestinal como conseqüência da formação de ácidos graxos de cadeia curta (AGCC) pela fermentação de FOS (WANG e GIBSON, 1993; ROBERFROID, 1993). A diminuição no número de bactérias nocivas (como Escherichia coli, Clostridium, Streptococcus faecallis e Proteus) tem como conseqüência o decréscimo de metabólitos tóxicos como amônia, indol, fenóis e nitrosaminas (CUMMINGS, MACFARLANE e ENGLYST, 1993).

MODLER (1994) verificou que a adição de neosugar à dieta humana (15 g/dia) causou acréscimo de dez vezes na população de bifidobactérias do intestino grosso, bem como a ocorrência de bifidobactérias passou de $87 \%$ para $100 \%$. Concomitantemente, houve redução de 0,3 unidade no $\mathrm{pH}$ intestinal e também decréscimo na contagem de enterobactérias. Em estudos similares, HIDAKA e HIRAYAMA (1991) verificaram que a administração de $8 \mathrm{~g} /$ dia de neosugar na dieta humana aumenta a produção de ácidos graxos.

WANG e GIBSON (1993) destacaram os seguintes aspectos benéficos atribuídos às bifidobactérias: são imunomoduladoras contra células malignas; produzem vitaminas do complexo $\mathrm{B}$ e ácido fólico; produzem enzimas digestivas e a lisozima; e restauram a biota intestinal normal após antibioticoterapia.

No tocante à dose bifidogênica de FOS, autores como ROBERFROID, VAN LOO e GIBSON (1998) afirmaram que cerca de $4 \mathrm{~g}$ por dia seriam suficientes para um adulto.

BOUHNIK (1996) demonstrou que a ingestão de FOS, em doses de 12,5 g/dia durante três dias (doses clinicamente toleradas), produz decréscimo na contagem de anaeróbios totais nas fezes e diminuição de $\mathrm{pH}$, da atividade de nitrorredutases, das concentrações de bile ácida e dos níveis séricos de colesterol total e lipídios.

\subsection{EFEITOS NA CARCINOGÊNESE E NA RESPOSTA IMUNE}

Modelos in vivo envolvendo ratos têm demonstrado a influência favorável dos FOS na inibição da carcinogênese do cólon. REDDY, HAMID e RAO (1997) induziram lesões pré-cancerosas em ratos usando azozimetano e os alimentaram com dietas contendo $10 \%$ de FOS, tendo verificado redução significativa das lesões.

TAPER e ROBERFROID (1999) implantaram células tumorais de dois tipos (hepáticas e mamárias) em ratos. Após tratamento com $150 \mathrm{~g} / \mathrm{kg}$ de FOS verificaram redução no crescimento dos tumores, quando comparados com placebo. Em outro estudo, TAPER et al. (1995) constataram que os FOS agem reduzindo a glicose e que as células tumorais assim prejudicadas em seu aporte de energia não conseguem se desenvolver. Outro mecanismo de ação dos FOS na inibição do crescimento tumoral ocorreria via formação de ácidos graxos de cadeia curta, mais precisamente, pelo aumento da formação do butirato (considerado agente antineoplásico em potencial) (GAMET et al., 1992).

Alguns estudos têm demonstrado que ratas alimentadas com FOS diminuíram a produção de certos metabólicos associados ao câncer (ROWLAND et al., 1998; BUDDINGTON, DONAHOO e BUDDINGTON, 2002). 
REDDY, RAMID e RAO (1997) utilizaram químico mutagênico específico em ratos e observaram menor formação de focos de colônias aberrantes ligadas ao câncer do cólon quando alimentadas com FOS. Já nas pesquisas de PIERRE et al. (1995) foi constatada redução na taxa de formação de tumores no intestino delgado e no cólon, depois que as cobaias consumiram FOS junto com a dieta. Tais resultados foram confirmados por BUDDINGTON, DONAHOO e BUDDINGTON (2002). Estudos realizados com animais mostraram que os probióticos tem efeito regulador no sistema imunológico e suspeita-se que o mesmo possa ocorrer em humanos (ERICKSON e HUBBARD, 2000; WOLD, 2001).

\subsection{EFEITO NO METABOLISMO DOS LIPÍDIOS}

DELZENNE et al. (1993) relataram o decréscimo dos triacilgliceróis no sangue de ratos alimentados com dietas contendo $20 \%$ de FOS e $10 \%$ de inulina. Tal resultado concorda com FIORDALISO et al. (1995) que observaram redução de 15\% nas taxas do colesterol total e decréscimo de $15 \%$ nos fosfolipídios e $25 \%$ nos triacilgliceróis em ratos após a ingestão de $10 \%$ de FOS.

Os efeitos hipolipidêmicos dos FOS foram observados também em humanos. DAVIDSON et al. (1998) conduziram experimento com indivíduos cujos níveis de lipídios estavam levemente alterados no sangue. Verificaram diminuição de 8,7\% na concentração de colesterol total e de $14,4 \%$ na concentração de LDL-colesterol, após a ingestão de $18 \mathrm{~g}$ por dia de inulina. VAN LOO et al. (1998) ressaltaram a existência de evidências suficientes sobre a modulação lipídica em animais, porém destacaram a necessidade de estudos com humanos utilizando modelos experimentais adequados.

\subsection{EFEITOS NAABSORÇÃO DE MINERAIS}

Testes de laboratório demonstraram aumento na absorção de minerais como cálcio, magnésio e fósforo mediante a ingestão de FOS. Ratos com dieta suplementada com FOS $(1,2$ e $5 \%$ ) tiveram o pH intestinal diminuído de forma dose dependente e a absorção de magnésio aumentada de forma linear. Os macrominerais ( $\mathrm{Ca}, \mathrm{P}, \mathrm{Mg}, \mathrm{Na}, \mathrm{Cl}$ e K) evidenciaram balanço positivo para os 3 tratamentos (WOLF, FIRKINS e ZHANG, 1998).

LOPEZ, COUDRAY e LEVRAT-VERNY, (2000) estudaram a administração de diferentes dietas em ratos (dieta livre de fibras, dieta livre de fibras $+7 \mathrm{~g} \mathrm{~kg}^{-1}$ de ácido fítico, considerado anti fator para a absorção de minerais, dieta contendo $100 \mathrm{~g} \mathrm{~kg}^{-1}$ de FOS e dieta contendo FOS $+7 \mathrm{~g} \mathrm{~kg}^{-1}$ de ácido fítico). Verificaram que a dieta com FOS aumentou a absorção de $\mathrm{Ca}$ e $\mathrm{Mg}$ no intestino. A absorção aparente de minerais aumentou significativamente pela ingestão de FOS (Ca $+20 \%$, $\mathrm{Mg}+50 \%, \mathrm{Fe}+23 \%, \mathrm{Cu}+45 \%)$ e diminuiu pela ingestão de ácido fítico para elementos traço ( $\mathrm{Fe}-48 \%, \mathrm{Zn}-62 \%, \mathrm{Cu}-31 \%)$. Por outro lado, a dieta que não continha fibras mas foi adicionada com ácido fítico apresentou resultado negativo no sangue (diminuição de $\mathrm{Mg}$ e Fe), fígado (diminuição de $\mathrm{Mg}$, Fe e Zn) e ossos (diminuição de Zn). A introdução de FOS na dieta com ácido fítico combate esses efeitos negativos, estimulando a hidrólise bacteriana do ácido fítico e melhorando a absorção intestinal dos minerais.

Evidências apontam para maior absorção de cálcio em humanos, acompanhado de aumento da densidade da massa óssea devido ao consumo de FOS, indicando redução de risco de osteopenia e osteoporose (VAN LOO et al., 1998). VAN DEN HEUVEL et al. (1999) conduziram estudos in vivo com jovens que receberam $15 \mathrm{~g}$ por dia de inulina e observaram aumento na absorção de cálcio. $\mathrm{O}$ aumento da absorção mineral parece estar relacionado com o tipo e quantidade de FOS e minerais presentes na dieta. Tais autores destacaram a necessidade de outros estudos que confirmem esse efeito. 


\subsection{OUTROS EFEITOS DOS FRUTOLIGOSSACARÍDEOS}

TAPER et al. (1995) verificaram efeito protetor dos FOS contra a atrofia induzida por deficiência de cobre ou excesso de frutose. YOUNES et al. (1996) constataram que a mistura de fibras, incluindo FOS, reduz a taxa de uréia no soro sanguíneo de ratos via excreção fecal de uréia. Os efeitos seriam devidos à conversão do $\mathrm{NH}_{3}$ a $\mathrm{NH}_{4}{ }^{+}$, menos tóxico (JENKINS, KENDALL e VUKSAN, 1999).

Os FOS exercem ação de imunomoduladores via bifidobacterium, auxiliando o ataque imunológico contra células malignas ou bactérias putrefativas e resistência adquirida do hospedeiro contra fungos patógenos (GIBSON e ROBERFROID, 1995).

\section{FRUTOLIGOSSACARÍDEOS DA YACON E A SAÚDE HUMANA}

A evidência dos efeitos promissores que a yacon poderia exercer sobre a saúde humana, ainda é indireta e provem de estudos realizados com frutanos purificados da chicória ou sintéticos. Pode-se apenas inferir que a yacon compartilha das mesmas propriedades descritas em estudos realizados com FOS da chicória (YAMAMOTO, 1999; LOPEZ, COUDRAY e LEVRAT-VERNY, 2000).

Como até o momento, os estudos têm sido realizados apenas com animais é necessário validar os resultados com estudos clínicos em humanos (BRADY, GALLAHER e BUSTA, 2000; CONWAY, 2001).

\section{VALOR CALÓRICO}

Os FOS apresentam cerca de um terço do poder adoçante da sacarose e não são calóricos, não podem ser considerados carboidratos ou açúcares nem fonte de energia, mas podem ser usados de modo seguro por diabéticos.

FLAMM et al. (2001) avaliaram o valor calórico dos FOS e constataram que o rendimento de energia para o hospedeiro estaria na faixa de 1,5 a 2,0 kcal/g. Usando outra metodologia, baseada no balanço da lipogênese, ROBERFROID et al. (1993) afirmaram que o valor calórico dos FOS está em torno de 1,0 a $1,5 \mathrm{kcal} / \mathrm{g}$.

Os FOS não são degradados durante a maioria dos processos de aquecimento, mas em condições muito ácidas ou exposição prolongada ao binômio tempo e temperatura podem ser hidrolisados em frutose (YUN, 1996). Suas características incluem: maior solubilidade que a sacarose, não cristalizam, não precipitam e nem deixam sensação de secura ou areia na boca (BORNET, 1994).

\section{TOXICIDADE}

Numerosos estudos in vitro e in vivo têm sido conduzidos para avaliar a toxicidade dos FOS, tanto em animais quanto em humanos (TOKUNAGA, OKU e HOSOYA, 1986).

Os estudos in vitro para determinar o potencial tóxico em animais incluíram o teste de mutação microbiana reversa, o teste de mutação de genes e o teste de síntese não-programada de DNA. Os testes não evidenciaram qualquer potencial genotóxico, carcinogenético nem toxicidade subcrônica (CLEVENGER et al., 1988).

ALLES et al. (1997) e DAVIDSON et al. (1998) observaram a aparição de flatulência em indivíduos que consumiram dietas contendo entre $15 \mathrm{~g}$ e $18 \mathrm{~g}$ por dia de FOS. A ingestão de FOS, associada à flatulência é mais flagrante em indivíduos com intolerância a lactose. A gravidade desse tipo de sintoma está relacionada com a dose de FOS consumida. A ingestão de 20-30 g por 
dia geralmente desencadeia o início de desconforto severo no indivíduo, sendo melhor seguir as doses recomendadas ( $10 \mathrm{~g} / \mathrm{dia}$ ). Somente pessoas muito sensíveis ( $1 \%$ a $2 \%$ da população) sofrem diarréia ou intolerância gastrintestinal com doses de $10 \mathrm{~g} /$ dia (COUSSEMENT, 1999). O consumo médio per capta de inulina na dieta européia varia de 2 a $12 \mathrm{~g} / \mathrm{dia}$, na Bélgica esse valor sobre para 5-8 g/dia, chegando a 7-12 g/dia na Espanha (MODLER, 1994).

Como status legal, os FOS são considerados ingredientes e não como aditivos alimentares na maioria dos países. São fibras dietéticas, confirmadas pelas autoridades legais e nos Estados Unidos adquiriram o status Generally recognized as safe (GRAS) (KOLBYE et al., 1992).

\section{CONCLUSÃO}

É inquestionável a comprovação das propriedade funcionais atribuídas aos FOS, principalmente sua ação como fibra alimentar, diante dos resultados narrados pela literatura dos últimos 15 anos. Muitos estudos têm sido conduzidos para assegurar os efeitos dos FOS sobre a microbiota intestinal, sua atividade anticarcinogênica e sobre as taxas de colesterol e glicemia no sangue. Acredita-se que conforme os estudos se tornem cada vez mais conclusivos a indústria aumentará consideravelmente a oferta de alimentos enriquecidos com essa fibra alimentar nutricionalmente ativa.

\section{ABSTRACT}

\section{FRUCTOLIGOSACCHARIDES: ACTIVE DIETARY FIBERS}

The objective of this review was to highlight the importance of the use of fructoligosaccharides (FOS) for human consumption and to present their effects as prebiotic ingredients. FOS chemical structure, industrial processing approaches, physical and chemical properties, effect in human health, caloric value and toxicity had been discussed. It is unquestionable to corroborate the functional properties attributed to FOS, mainly due to its action as dietary fiber, based on the results reported in the last 15 years literature. Many studies have been carried out to assure the effects of FOS over the gut microbiota, including their anticarcinogenic properties and activity on levels of blood cholesterol and glycemia. It is believed that as the studies become more conclusive, the industry will increase considerably the range of food products enriched with this highly active dietary fiber.

KEY-WORDS: FRUCTOLIGOSACCHARIDES; INULIN; PREBIOTIC EFFECTS; DIETARY FIBERS.

\section{REFERÊNCIAS}

1 ALLES, M.S.; de ROSS, N.M.; BAKX, J.C.; VAN DE LISDONK, E.; ZOCK, P.L.; J.G. HAUTVAST. Consumption of fructooligosaccharides does not favorably affect blood glucose and serum lipid concentrations in patients with type 2 diabetes. American Journal of Clinical Nutrition, v. 69, p.64-69, 1999.

2 BORGES, V. C. Impactos dos alimentos para a saúde. Nutrição em Pauta, São Paulo, n. 48, p.17-18, 2001.

3 BORNET, F.R.J. Non digestible sugars in food products. American Journal of Clinical Nutrition, v. 59, p.7635-7695, 1994.

4 BOUHNIK, Y. Effects of fructo-oligosaccharides ingestion on fecal bifidobacteria and selected metabolic indexes of colon carcinogenesis in healthy humans. Nuti. Cancer, Paris, v.26, n.1, p.21-29, 1996.

5 BRADY, P. L.; GALLAHER, D.; F. BUSTA. The role of probiotic culture in the prevention of colon cancer. Journal of Nutrition, v. 130, p. 410s-415s, 2000.

6 BUDDINGTON, K.K.; DONAHOO, J.B.; BUDDINGTON, R.K. Dietary oligofructose and inulin protect mice from enteric and systemic pathogens and tumor inducers. The Journal of Nutrition, v.132, n.3, p.472-477, 2002.

7 CleVENGER, M.A.; TURNBULL, D.; INOUE, H.; ENOMOTO, M.; ALLEN, J.A.; HENDERSON, L.M.; JONES, E. Toxicological evaluation of neosugar: genotoxicity, carcinogenicity and chronic toxicity. Journal of American College of Toxicology, v.7, p.643-662, 1988. 
8 CONWAY, P.L. Prebiotics and human health: the state-of-the-art and future perspectives. Scandinavian Journal of Nutrition, v.45, p.13-21, 2001.

9 COUNDRAY, C.; BELLANGER, J.; CASTIGLIA-DELAVAUD, C.; REMESY, C.; VERMOREL M.; RAYSSIGNUIER, Y. Effect of soluble or partly soluble dietary fibres supplementation on absorption and balance of calcium, magnesium, iron and zinc in healthy young men. European Journal of Clinical Nutrition, v. 51, p.375-380, 2003.

10 COUSSEMENT, P.A.A. Inulin and oligofructose: safe intakes and legal status. Journal of Nutrition, v.129, p.14125$14175,1999$.

11 CUMMINGS, J. H.; MACFARLANE, G. R; ENGLYST, H.N. Prebiotic digestion and fermentation. American Journal of Clinical Nutrition, v.73, p.415S-420S, 1993.

12 DAVIDSON, M.H.; MAKI, K.C.; SYNECKI, C.; TORRI, S.A.; DRENNAN, K.B. Effects of dietary inulin in serum lipids in men and woman with hypercholesterolemia. Nutrition Research, v.18, n.3, p. 503-517, 1998.

13 DELZENNE, N.M.; KOK, N.; FIORDALISO, M. F.; DEBOYSER, D.M.; GOETHALS, F.M.; ROBERFROID, M.B. Dietary fructoligossacharides modify lipid metabolism. American Journal of Clinical Nutrition, v. 57, n.5, p.820S, 1993.

14 DREVON, T.; BORNET, F. Lês FOS: ACTILIGHT. In: MULTON, J. L. (Ed.). Le sucre, les sucres, les edulcorants et les glucides de charges dans les IAA. Paris: Tec \& DOC Lavoisier, 1992. p. 313-338.

15 ERICKSON, K.L.; HUBBARD, N.E. Probiotic immunomodulation in health and disease. Journal of Nutrition, v.130, p.403S-409S, 2000.

FAGUNDES, R.L.M.; COSTA, Y.R. Uso de alimentos funcionais na alimentação. Higiene Alimentar, v.17, n. 108, p. 42$48,2003$.

17 FIORDALISO, M.; KOK, N.; DESAGER, J.P.; GOETHALS, F.; DEOYSER, D.; ROBERFROID, M.; DELZENNE, N. Dietary oligofructose lower triglycerides, phospholipids and cholesterol in serum and very low density lipoproteins of rats. Lipids, v.30, n.2, p.163-167, 1995.

18 FLAMM, G.; GLINSMANN, W.; KRITCHEVSKY, D.; PROSKY, L.; ROBERFROID, M. Inulin and oligofructose as dietary fiber: a review of the evidence. Critical Reviews in Food Science and Nutrition, Ohio, v.41, n.5, p. 353-362, 2001.

19 GAMET, L.; DAVAIND, D.; DENIS-POOUXVIEL C.; RAMSEY C.; MURAT, J. C. Effects of short-chain fatty acids on growth and differentiation of the human colon cancer cell line HT 29. Int. J. Cancer, v.52, p. 286-289, 1992.

20 GIBSON, G. R.; ROBERFROID, M. B. Dietary modulation of the human colonic microbiota: introducing the concept of prebiotics. J. Nutr., Cambridge, v.125, n.6, p.1401-1412, 1995.

21 GIBSON G. R.; WILLIS C. L.; VAN LOO J. Non-digestible oligosaccharides and bifidobacteria implications for health. Int. Sugar J., v.96, p.1150-1156, 1994.

22 GOTO, K.; KATSUHITO, F.; HIKIDA, J.; NANJO, F.; HARA, Y. Isolation and structural analysis of oligosaccharides from yacon (Polymnia sonchifolia). Bioscience, Biotechnology, and Biochemistry, v.59, n.12, p.2346-2347, 1995.

23 HARTEMINK, R.; VANLAERE, K.M.J.; ROMBOUTS, F.M. Growth of enterobacteria on fructo-oligosaccharides. Journal of Applied Microbiology, v.383, p.367-374, 1997.

24 HIDAKA, H.; HIRAYAMA, M. Useful characteristics and commercial application of fructooligosaccharides. Biochemical Society Transactions, v.19, p.561-565, 1991.

25 HONDO, M.; OKUMURA, Y.; YAMAKI, T. A preparation of yacon vinegar containing natural fructooligosaccharides. Journal of the Japanese Society for Food Science and Technology-Nippon Shokuhin Kagaku Kogaku Kaishi, Hokkaido, v.47, n.10, p.803-807, 2000.

26 JENKINS, J.A.; KENDALL, C.W.C.; VUKSAN, V. Inulin, oligofructose and intestinal function. Journal of Nutrition, v.129, p.1431s-1433s. 1999.

27 KOLBYE, A. C. et al. Evaluation of the food safety aspects of inulin and oligofructose-GRAS determination. Orafti internal report. Tienen, Belgium, 1992. Disponível: < http://www.orafti.com>. Acesso em: 17 de maio de 2003.

28 LOPEZ, H.W.; COUDRAY, C.; LEVRAT-VERNY, M.A. Fructooligosaccharides enhance mineral apparent absorption and counteract the deleterious effects of phytic acid on mineral homeostasis in rats. J. Nutr. Biochem., v.11. p.500-508, 2000.

29 MODLER, H.W. Bifidogenic factors - sources, metabolism and applications. Internartional Dairy Journal, v.4, p. 383407, 1994.

30 MOLIS, C. et al. Digestion, excretion and energy value of fructooligosaccharides in health humans. American Journal of Clinical Nutrition, v.64, p.324-328, 1996. 
31 MORO, G. et al. Dosage-related bifidogenic effects of galacto- and fructooligosaccharides in formula-fed term infants. Journal of Pediatric Gastroenterology and Nutrition, v.34, p.291-295, 2002.

32 NINESS K.R. Inulin and oligofructose. What are they? Journal of Nutrition, v.129, p.1402s-1406s, 1999.

33 PEREIRA, D. I; GIBSON, G. R. Effects of consumption of probiotics and prebiotics on serum lipid levels in humans. Crit. Rev. Biochem. Mol Biol. v.37, p.259-281, 2002.

34 PIERRE, F; PERRIN, P.; CHAMP, M.; BORNET, F.; MEFLAH, K.; MENANTEAU, J. Short-chain fructo-oligosaccharides reduce the occurence of colon tumours and develop gut-associated lymphoid tissue in min mice. Cancer Research, v.57, p.225-228. 1995.

PROSKY, L.; HOEBREGS, H. Methods to determine food inulin and oligofructose. Journal of Nutrition, v. 129, p. 14185-14235, 1999.

36 QUINTEROS, E.T.T. Produção com tratamento enzimático e avaliação do suco de Yacon. Campinas, 2000.96 p. Tese (Doutorado em Tecnologia de Alimentos) - Faculdade de Engenharia de Alimentos, Universidade Estadual de Campinas.

37 REDDY, B.S.; HAMID, R.; RAO, C.V. Effect of dietary oligofructose and inulin on colonic preneoplastic aberrant crypt foci inhibition. Carcinogenesis, v.18, n.7, p.1371-1374, 1997.

38 ROBERFROID, M. Dietary fiber, inulin, and oligofructose: a review comparing their physiological effects. Critical Rev. Fd. Sci. Nutr. v. 33, p.103-148, 1993.

39 ROBERFROID, M.B.; VAN LOO, J.A.E.; GIBSON, G.R. The bifidogenic nature of chicory inulin and its hydrolisis products. Journal of Nutrition, v.128, p.11-19, 1998.

40 ROBERFROID, M.B. Caloric value of inulin and oligofructose. Journal of Nutrition, v.129, p.1436s-1437s, 1999.

41 ROWLAND, I. R.; RUMNEY, C.J.; COUTTS, J.T.; LIEVENSE, L.C. Effects of Bifidobacterium longum and inulin on gut bacterial metabolism and carcinogen-induced aberrant crypt foci in rats. Carcinogenesis, v.19, n.2, p.281-185, 1998.

42 SCHNEEMAN, B.O. Fiber, inulin and oligofructose: similarities and differences. Journal of Nutrition, v.129, p.1424S1427S, 1999.

43 SPIEGEL, J.E.; ROSE, R.; KARABELL, P. Safety and benefits of fructooligosaccharides as food ingredients. Food Technology, Boston, v.48, p.85-89, 1994.

44 STRICKLING, J.A. Evaluation of oligosaccharides addition to dog diets: influences on nutrient digestion and microbial populations. Anima Feed Sci. Nad. Technol., Topeka, v.86, p.205-219, 2000.

45 TANAKA, R.; MATSUMOTO, K. Recent progress on prebiotics in Japan, including galacto-oligosaccharides as food ingredients. Food Technology, v.336, p.1488s-1491s, 1998.

46 TAPER, H.S.; DELZENNE, N.; TSHILOMBO, A.; ROBERFROID, M.B. Protective effect of fructo-oligosaccharide in young rats against exocrine pancreas atrophy induced by high fructose and partial copper deficiency. Food Chemical Toxicology, v.33, n.8, p.631-639, 1995.

47 TAPER, H.S.; ROBERFROID, M.B. Influence of inulin and oligofructase on breast cancer and tumor growth. Journal of Nutrition, v. 129, p.1488s-1489s, 1999.

48 TOKUNAGA, T.; OKU, T.; HOSOYA, N. Influence of chronic intake of new sweetener fructooligosaccharide (neosugar) on growth and gastrointestinal function of rat. Journal of Nutrition Science and Vitamilology, v.32, p. 111-121, 1986.

49 VAN DEN HEUVEL, E.G.H.M.; MUYS T.; VAN DOKKUM, W.; SCHAAFSMA, G. Oligofructose stimulates calcium absorption in adolescents. American Journal of Clinical Nutrition, v. 69, p.544-548, 1999.

50 VAN LOO, J.; CUMMINGS, J.; DELZENNE, N.; ENGLYST, H.; FRANCK, A.; HOPKINS, M.; KOK, N.; Mc FARLANE, G.; NEWTON, D.; QUIGLEY, M.; ROBERFROID, M.; VAN VLIET, T.; VAN DEN HEUVEL, E. Functional food properties of non-digestible oligosaccharides: a consensus report from the ENDO project (DGXII - CT94-1094). British Journal of Nutrition, v.81, p.121-132, 1998.

51 WANG, X.; GIBSON, G.R. Effects of the in vitro fermentation of oligofructose and inulin by bacteria growing in the human large intestine. J. Appl. Bacteriol., Cambridge, v.74, n.4, p.373-380, 1993.

52 WOLD, A.E. Imunne effects of probiotics. Scandinavian Journal of Nutrition, v. 129, p. 76-85, 2001.

53 WOLF, B.W.; FIRKINS, J.L.; ZHANG, X. Varying dietary concentrations of fructooligosaccharides affect apparent absorption and balance of minerals in growing rats. Nutrition Research, Columbus, v.18, n.10, p.1791-1806, 1998.

54 YAMAMOTO, Y. In vitro digestibility and fermentability of levan and it hypocholesterolemic effects in rats. J. Nutr. Biochem., Osaka, v.10, p.13-18, 1999. 
55 YOUNES H.; DEMIGNÉ, C.; BEHR, S.R.; GARLEB, K.A.; RÉMÉSY, C. A blend of dietary fibers increases urea disposal in the large intestine and lowers urinary nitrogen excretion in rats fed a low protein diet. Nutritional Biochemistry, v.7, p.474-480, 1996.

56 YUN, J.W. Fructooligosaccharides - occurence, preparation and application. Enzyme and Microbial Technology, v.19, p.107-117, 1996.

57 ZULETA, A.; SAMBUCETTI, M.E. Frutanos: características estruturales y metodologia analítica. In: CARBOHIDRATOS en alimentos regionales Iberoamericanos. São Paulo: Editora da Universidade de São Paulo, 2006. p.199-210. 